\section{MARTÍN GARCÍA MÉROU. \\ VIDA INTELECTUAL Y DIPLOMÁTICA \\ EN LAS AMÉRICAS}

de Paula Bruno,

Bernal, Universidad Nacional de Quilmes,

2018, 211 pp.

RAQUEL BRESSAN

Universidad Nacional de General Sarmiento (Argentina).

Email: vbressan@ungs.edu.ar

En Martín García Mérou. Vida intelectual y diplomática en las Américas, Paula Bruno presenta una selección de dieciocho obras de Mérou acompañadas por un estudio preliminar que recrea el contexto de producción de aquellos textos y el criterio de su selección en base a tres ejes de análisis: las miradas y estudios sobre las dinámicas culturales de naciones latinoamericanas; cartografía de la vida intelectual argentina y análisis de García Mérou sobre la reconfiguración del escenario geopolítico americano y sus ecos en la vida intelectual del cambio de fin de siglo. A partir de la construcción de estos ejes las obras son insertadas desde una mirada orgánica que permite superar un relato lineal y anecdótico de su producción, así como de la propia vida y quehacer intelectual de su autor. De esta forma, a través de las páginas del ensayo, Bruno nos invita a acompañar la trayectoria del intelectual cual turistas curiosos que nos deleitamos con un nuevo enfoque de los aspectos más celebrados de aquella figura y nos sorprende al reponer aspectos menos conocidos del itinerario que permitió dar vida a los textos que componen la antología.

En el primer eje se analiza la impronta que la labor diplomática tuvo en la pluma del intelectual. Como advierte Bruno, si Paris bloqueó el impulso del descubrimiento al ser observada bajo el lente de las lecturas que un joven Mérou había consumido en Buenos Aires, Colombia y Venezuela constituyeron un serio desafío narrativo. Para escapar del tradicional exotismo literario y describir los espacios latinoamericanos, señala la autora, «forjó lo que sería una de sus marcas de autor: emprendió el estudio sistemático del ámbito letrado de cada uno de los lugares a los que lo llevó su carrera diplomática». Así, en la escritura de «De paso por Río de 
Janeiro. En París. Recuerdos de Venezuela y Colombia» y de «El Brasil intelectual» - ambos textos incluidos en la antología- se observa el estudio minucioso de los espacios de sociabilidad y de las voces de la vida letrada de las ciudades latinoamericanas que constituyeron el tránsito de su carrera diplomática.

En el segundo eje se reconstruye las apreciaciones del mundo cultural argentino elaboradas por Mérou. A partir del análisis de un significativo número de textos, Bruno restituye una secuencia temporal formada por cuatro momentos claramente diferenciados del ámbito letrado en el Río de La Plata. El primero constituido por los intelectuales que pensaron al país desde el exilio durante la etapa rosista. Un segundo momento ubicado en la década de I870 se hallaba marcado por la efervescencia de la vida literaria y la convivencia de los antiguos exiliados con los hombres del interior y los extranjeros que se integraron a los ámbitos culturales locales. El tercer momento, ubicado a mediados de la década de I880 muestra la ambigüedad de las apreciaciones de Mérou en las cuales se combinaban el optimismo por el desarrollo de la literatura nacional con ciertas notas de pesimismo vertidas a través de ciertos comentarios realizados durante sus breves estancias en el país. El último momento se vincula directamente a la crisis de 1890 y a las críticas del devenir cultural y el rol que el Estado debía desempeñar en el mismo.
El tercer eje analiza la mirada de Mérou sobre episodios críticos de la vida política americana en los cuales tuvo una participación privilegiada desde su rol diplomático. Así, por ejemplo, se hallaba en Brasil durante la firma del Laudo de Cleveland que resolvió los conflictos limítrofes entre Argentina y Brasil por el territorio de las Misiones Orientales en I895 y se desempeñó activamente en la Segunda Conferencia Panamericana realizada en México durante I90I y 1902. A partir de escritos como «De paso por Chicago», «American ideals», «La Primera Conferencia Panamericana en Washington», «La cuestión de Cuba y la Guerra entre España y Estados Unidos», el ya citado «Brasil intelectual» y los artículos que escribió para el diario $\mathrm{La}$ Nación como corresponsal, Bruno destaca que la mirada de Mérou sobre el lugar de Brasil y Estados Unidos en un contexto de significativos cambios geopolíticos se desarrolló en contramarcha de las tendencias dominantes en el mundo intelectual, arraigada en el conocimiento exhaustivo que tenía de ambos países.

La elaboración de los tres ejes aquí citados no sólo contextualiza el marco de producción de los textos que conforman la antología. Más aún, la detallada y fructífera recopilación de fuentes (que incluye cartas y documentos del Archivo Histórico de la Cancillería Argentina y del Fondo Martín García Mérou; artículos de diarios 
de Buenos Aires, París y Madrid) así como el nutrido diálogo que Bruno entabla con estudiosos de la figura de Mérou pertenecientes a distintas latitudes, devuelve una imagen desencasillada de este intelectual y permite apreciar como su obra fue recepcionada y repensada en distintas escalas temporales y geográficas.

Martín García Mérou nació en I862, año fundacional en la historia política en tanto marcaba el inicio de la presidencia de Bartolomé Mitre tras la incorporación de Buenos Aires a la Confederación Argentina. La conformación del Estado nacional con la creación de nuevas instituciones fue el marco de pródigas oportunidades para un conjunto heterogéneo de hombres que desplegaron su carrera profesional en forma paralela a la construcción de este nuevo Estado. Aquel contexto constitutivo de la Nación permeó en diferentes aspectos y con distintiva incidencia labor intelectual de un segmento de aquellos hombres dentro de los cuales se ubica a Mérou y que pasaron a la pros- peridad bajo el rótulo de miembros de la "Generación del 80». Sin embargo, a diferencia de buena parte de sus pares, residió la mayor parte de su vida en el extranjero y para él, apunta Bruno, «la diplomacia no fue una ocupación entre otras, sino el vector de su itinerario público que, además, condicionó la forma de articular las dimensiones intelectuales con la vida de las legaciones». Por lo tanto, a partir de la intrínseca articulación de su labor intelectual y cultural Martín García Mérou inauguró una nueva categoría dentro del ámbito letrado que Bruno denomina como la del intelectual-diplomático. Martín García Mérou. Vida intelectual y diplomática en las Américas constituye un valioso aporte para todos aquellos interesados en la historia intelectual e incorpora una nueva coordenada al complejo y rico mapa de la vida cultural argentina de la segunda mitas de siglo xIx y principios del xx, al cual Paula Bruno, a partir de sus estudios, ha colaborado en forma pródiga a construir. 